\title{
Tracking pores during solidification of a Ni-based superalloy using 4D synchrotron microtomography.
}

\author{
E. Plancher ${ }^{1}$, P. Gravier ${ }^{1}$, E. Chauvet ${ }^{1}$, J.-J. Blandin ${ }^{1}$, E. Boller ${ }^{2}$, \\ G. Martin ${ }^{1, *}$, L. Salvo ${ }^{1}$, P. Lhuissier ${ }^{1, *}$ \\ 1 Université Grenoble Alpes, CNRS UMR5266, Grenoble INP, Laboratoire \\ SIMaP, 38000 Grenoble, France. \\ 2 ESRF-The European Synchrotron, CS40220, 38043, Grenoble Cedex 9, \\ France \\ *corresponding authors: guilhem.martin@ simap.grenoble-inp.fr (G. Martin), \\ pierre.lhuissier@simap.grenoble-inp.fr (P. Lhuissier)
}

\begin{abstract}
Time-resolved in situ microtomography is employed to track the nucleation and growth of individual pores during solidification of a commercial nickel-based superalloy. Three cooling rates $(0.1,0.5$ and $1{ }^{\circ} \mathrm{C} / \mathrm{s}$ ) are investigated to evaluate the effect of this key processing parameter on the formation of porosity. Phase contrast obtained with a coherent X-ray beam is used to visualize the evolution of dendritic structures in absence of a sufficient absorption contrast. Two mechanisms leading to shrinkage pores have been identified. The first mechanism (mechanism A) is associated with the coalescence of secondary dendrite arms at temperature during the early stages of solidification. The second mechanism (mechanism B) is related to insufficient liquid feeding in the interdendritic region during the last stages of solidification, at lower temperatures. A variation of cooling rate by a factor 2 does not affect the nucleation rate of pores generated through mechanism B. However, it seems to affect the nucleation rate of small pores obtained through the mechanism A. The kinetics of growth for the majority of individual pores can be described using an exponential-like function. This kinetics is faster for mechanism B compared to mechanism A.
\end{abstract}




\section{Graphical abstract}

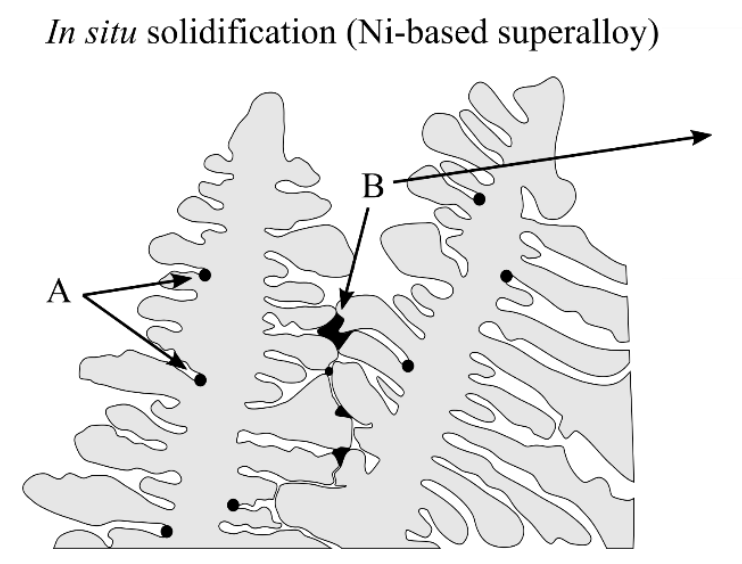

Tacking pores using ultra-fast tomography
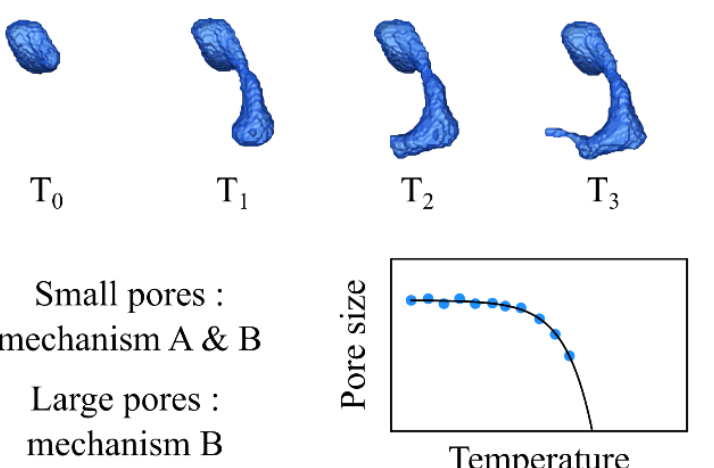

\section{Keywords}

Porosity; In situ; Solidification; Time-resolved microtomography, Nucleation; Growth; Superalloys 


\section{Introduction}

The control of shrinkage porosity in cast nickel-based superalloys is essential to extend the service life of jet engine components being operated at high-temperature under cyclic loads. Casting defects such as shrinkage pores are well-known nucleation sites for microcracks in low cycle fatigue $[1,2]$ as well as in high cycle fatigue [3]. Defect sizes ranging from a few microns to several hundreds of microns can affect fatigue properties but the largest defect is often considered as the key parameter that governs the fatigue resistance. Shrinkage pores also act as internal sinks for vacancies during creep deformation [4]. They can grow significantly to adopt a polyhedral shape and eventually contribute to extensive creep cavitation before failure [5]. In the late stages of creep, large pores are known to be nucleation sites for micro-crack as well [6,7].

The size, shape and distribution of casting pores in the microstructure are influential factors for fatigue and creep resistance. Typically, larger pores (of the order of few hundreds of microns) tend to promote stress concentration and pores with irregular shapes can encourage crack nucleation through notch-like effects. As an illustration, the creep resistance of superalloys below $1000^{\circ} \mathrm{C}$ can be improved significantly when the size and density of pores is decreased by hot isostatic pressing [8]. Also, fatigue life improvements in the low cycle regime, attributed to refined porosity, have been reported in single crystals [9]. Undoubtedly, it is of fundamental interest to understand the mechanisms leading to pores with contrasted sizes and shapes during solidification and to assess the effect of key processing parameters, such as the cooling rate, on their final characteristics.

$\mathrm{X}$-ray micro-tomography is a suited characterization tool to investigate porosity in millimeter-sized samples. It provides a 3D description of the sample internal structure, with a micrometer spatial resolution and with a high acquisition rate when performed at synchrotron radiation facilities [10]. Microtomography has been employed to investigate the pore population in superalloy single crystals, in relation with their chemical composition and processing parameters [11-13], and creep resistance [7,11]. Through ex situ measurements, only limited information can be gathered on pore formation and growth mechanisms occurring during solidification. In situ X-ray radiography first provided time-resolved insights into the phenomenon $[14,15]$. However, the recent introduction of CMOS cameras with ultra-fast acquisition rates has enabled the in situ monitoring of solidification processes [16-18]. This technological leap has been used to further investigate, for example, dendritic growth in model alloy systems, typically $\mathrm{Al}-\mathrm{Cu}$, showing a strong absorption contrast between the copper-enriched liquid and the solid phase [17,19-21]. Similarly, Hf-bearing alloys have been used to 
study $\mathrm{Ni}, \mathrm{Fe}$ and Co binary systems with a high melting temperature [22]. In those peculiar cases, the 3D morphology of the dendrites could be tracked accurately and the fraction of solid estimated because the absorption contrast between the liquid and the solid phase was pronounced. Thus mechanisms such as dendrite growth and coalescence were characterized.

In this work, real-time in situ "4D" microtomography was employed to track the formation and growth of individual pores during solidification of a commercial nickel-based superalloy. Three cooling rates were investigated $\left(0.1^{\circ} \mathrm{C} / \mathrm{s}, 0.5^{\circ} \mathrm{C} / \mathrm{s}\right.$ and $\left.1{ }^{\circ} \mathrm{C} / \mathrm{s}\right)$ to evaluate the effect of this key processing parameter on the formation of porosity. Phase contrast obtained with a coherent X-ray beam was used in order to visualize the evolution of corresponding dendritic structures because of the absence of sufficient absorption contrast. The mechanisms leading to two populations of pores with contrasted final characteristics, namely size and shape were identified. For the first time, the kinetics of pore nucleation and growth during solidification of a commercial Ni-based superalloy, depending on the cooling rate, is reported and discussed in relation to the resulting pore size and morphology.

\section{Experimental methods}

\subsection{Samples}

The material investigated was an industrial grade Ni-based superalloy containing substantial amount of $\mathrm{Co}, \mathrm{Cr}$ and $\mathrm{Mo}$, a combined amount of $\mathrm{Ti}$ and $\mathrm{Al}$ of $8.6 \mathrm{wt} \%$ and traces of $\mathrm{B}$. Its detailed chemical composition is proprietary and cannot be reported here. More details can be found in references [23-25], in particular in [25] where the contents of the main alloying elements are provided. The raw material was machined into cylindrical samples with a pin extending over a base, as shown in Figure 1a. The pin corresponded to the area being melted and solidified during the experiment and was therefore probed with X-ray microtomography. It had a diameter of $0.8 \mathrm{~mm}$ and a height of $1.6 \mathrm{~mm}$. The cylindrical base had a $4.5 \mathrm{~mm}$ diameter wide, a $5 \mathrm{~mm}$ height and featured a small hole designed to receive a thermocouple used to monitor the temperature during the experiment, in the immediate vicinity of the pin. 

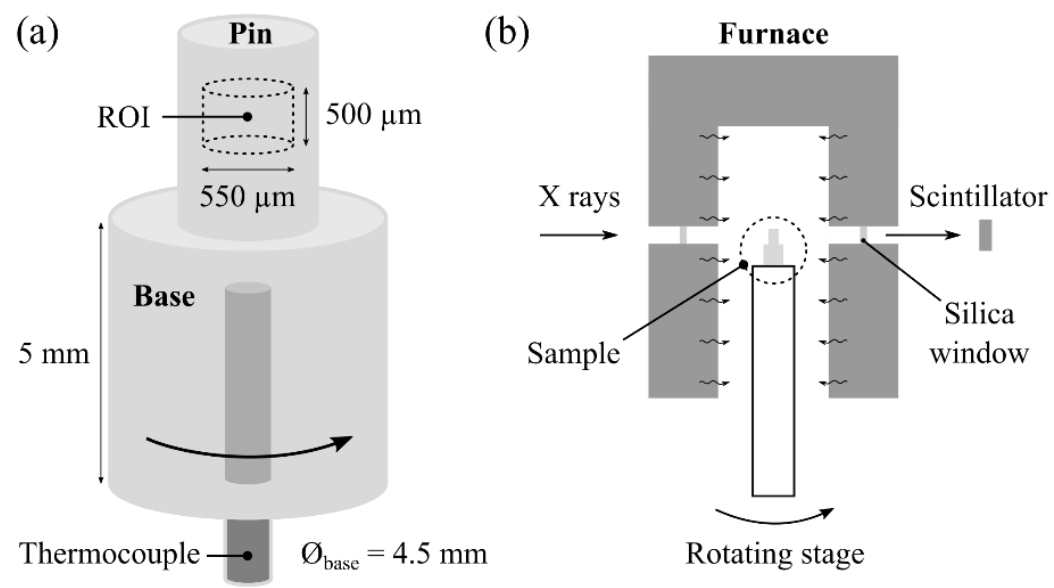

Figure 1. Overview of the setup used to perform in situ solidification experiments. (a) Schematic of the sample geometry. The region of interest (ROI) is located at the center of the pin (top part of the sample). A thermocouple was inserted in the base of the sample to monitor the temperature close to the ROI. (b) A furnace compatible with in situ time-resolved microtomography acquisitions was used to control the cooling rate of the sample.

\subsection{In situ solidification}

Solidification experiments were performed in situ on the microtomography setup available at beamline ID19 of ESRF. Prior to each solidification experiment, a sample was glued onto a tall alumina rod attached to a Leuven fast rotating stage. The sample was first melted in a resistive furnace specifically designed for samples with a millimetric size (courtesy of Mines ParisTech [19]) and then cooled down under controlled conditions within the furnace. A thin surface layer of oxide formed during the heating step and acted as a crucible. The furnace was equipped with two thin silica windows allowing to perform microtomography acquisitions all through the experiment (see Figure 1b). Three cooling rates were investigated: $0.1^{\circ} \mathrm{C} / \mathrm{s}$ $\left(5^{\circ} \mathrm{C} \cdot \mathrm{min}^{-1}\right), 0.5^{\circ} \mathrm{C} / \mathrm{s}\left(28{ }^{\circ} \mathrm{C} \cdot \mathrm{min}^{-1}\right)$ and $1^{\circ} \mathrm{C} / \mathrm{s}\left(62^{\circ} \mathrm{C} \cdot \mathrm{min}^{-1}\right)$.

Time-resolved microtomography measurements were performed with a pink beam set at a mean energy of $57 \mathrm{keV}$. A dedicated optical system with a $100 \mu$ m-thick LuAG scintillator and a x10 Mitutoyo objective lens was placed in front a PCO Dimax CMOS camera dedicated to fast recording. Each acquisition was completed under $3 \mathrm{~s}$ by taking 750 projections over $180^{\circ}$, and repeated every $12 \mathrm{~s}$ to $18 \mathrm{~s}$ depending on the cooling rate. The pixel size in the image was $1.22 \mu \mathrm{m}$. The region of interest considered was a cylindrical volume of $0.12 \mathrm{~mm}^{3}$, taken at the center of the pin, with a diameter of $550 \mu \mathrm{m}$ and a height of $500 \mu \mathrm{m}$ (see Figure 1a). The volume reconstruction was performed with a filtered back-projection algorithm, applying a correction for ring artefacts, in the software PyHST [26]. Phase contrast was retrieved with a Paganin method [27] set with a $\delta / \beta$ coefficient of $300, \delta$ being the refractivity index and $\beta$ the absorption contrast. 
A type $\mathrm{S}$ thermocouple, inserted in the base of the sample, was used to monitor continuously the temperature in the close proximity to the pin. To compensate for small systematic errors in the measurement, the temperature profile was shifted to read $1350^{\circ} \mathrm{C}$ (a value corresponding to the liquidus temperature for the investigated superalloy, see $[22,24])$ at time $t_{0}$ when solidification started. Time $t_{0}$ was chosen as the time during cooling of the last tomography scan showing a fully-liquid region of interest (i.e. no dendrites). The uncertainty on the temperature measurement is evaluated below $12^{\circ} \mathrm{C}$, the later value being related to the temperature change recorded between two successive microtomography acquisitions at the fastest cooling rate $\left(1^{\circ} \mathrm{C} / \mathrm{s}\right)$.

\subsection{Data processing and tracking method}

For each sample, a dataset of 17 acquisitions was selected at given temperatures distributed between $1350^{\circ} \mathrm{C}$, at which the sample was fully liquid, and $1150^{\circ} \mathrm{C}$, at which the sample was fullysolidified. In each dataset, a drift correction was employed to compensate the displacement of the region of interest (between two reconstructed volumes) associated with the thermal contraction of the sample holder. A registration algorithm was employed to calculate the rigid translation with a pixel accuracy, using the oxide layer as a stable source of contrast. A background subtraction was also carried out to remove long-range intensity gradients in the volume. For quantitative analysis of porosity, straightforward thresholding was performed based on the high contrast between (dark-looking) pores and the dense (liquid or solid) phase.

To track the evolution of individual pores in a dataset, a crossvolume labelling method was developed. First, a volume containing "virtual" pores was generated as an aggregation of all acquisitions over the full temperature range. Virtual pores represent an imprint of the size and shape the actual pores have occupied at different time during solidification, around a fixed position. Each actual pore in the dataset could then be associated with the virtual pore containing its center of gravity and labelled accordingly. Tortuous pores not containing their own center of gravity were associated to the closest virtual pore. This method was found very effective and random assessments did not reveal a significant number of mislabeling. Pores with a volume below 9 voxels were not considered in the quantitative analysis and so were excluded pores in contact with the edge of the cylinder delimiting the region of interest. The resolution limit set to 9 voxels corresponds to a 3D-cross whose maximum dimensions along $\mathrm{X}, \mathrm{Y}$ and $\mathrm{Z}$ are equal to 3 adjacent voxels. With a pixel size of $1.22 \mu \mathrm{m}$, this means a resolution of $3.66 \mu \mathrm{m}$. In other words, pores having an equivalent diameter smaller than $3.66 \mu \mathrm{m}$ have been 
discarded from our analysis. The sphericity index used in this work was defined as the ratio of the pore volume over the volume of a sphere with the same surface area as the pore. Image processing was performed with the platform Fiji [28] (ImageJ) and 3D views were obtained with the commercial software Avizo.

\section{Results and discussion}

\subsection{Impact of cooling conditions on the residual porosity}

The typical morphology of dendritic structures at the three imposed cooling rates is illustrated in Figure 2a-c. Cross sections were selected at about $1340^{\circ} \mathrm{C}$ for intermediate solid fractions. In those images, bright pixels are associated with the solid phase while dark grey pixels correspond to the liquid phase. Phase contrast was used to reveal the dendritic structures because absorption contrast was insufficiently pronounced in this commercial Ni-base superalloy. A weak absorption contrast is a direct consequence of the partitioning of alloying elements during solidification that, on average, gives a similar atomic number within the liquid phase and solid phase respectively. As a result, an accurate and automated estimation of solid fractions was not possible in our experiment. Hence only rough estimations based on 2D cross sections, are provided as reference in Figure 2. Note that the solid fraction estimation given for a cooling rate of $0.1^{\circ} \mathrm{C} / \mathrm{s}$ might not be reliable as the volume of region of interest is limited relative to the secondary dendrite arm spacing. In Figure 2a-c, a schematic associated with each 2D view highlights the dendrites size and morphology.

An estimation of the secondary arm spacing $\lambda_{2}$, carried out at high solid fraction and for a temperature of $1290^{\circ} \mathrm{C}$, is also presented in Table 1. The values measured are consistent with those reported for nickel-based superalloys in reference [29] and show that a satisfactory control of the cooling conditions was achieved in our experiments. As expected, finer dendritic structures are obtained at faster cooling rates. However, one should notice that we do not see a drastic variation of the secondary arm spacing given the range of cooling rates investigated. More significant differences would be observed if varying the cooling rates by several order of magnitude. At $1{ }^{\circ} \mathrm{C} / \mathrm{s}$ and $0.5^{\circ} \mathrm{C} / \mathrm{s}$ (Figure 2b and Figure 2c), a full dendrite can be identified in the $2 \mathrm{D}$ cross sections, with a trunk and secondary arms. Other features suggest the presence of surrounding dendrites with different orientations. This observation was confirmed by inspecting the whole volume from several angles. At $0.1^{\circ} \mathrm{C} / \mathrm{s}$, only large secondary dendrite arms are observed, see Figure 2a. In this case, the volume investigated using X-ray microtomography does not fully capture the coarse nature of the dendrite structure. To avoid a representativeness bias, this last dataset is not considered hereafter for porosity-related investigations. 
(a)

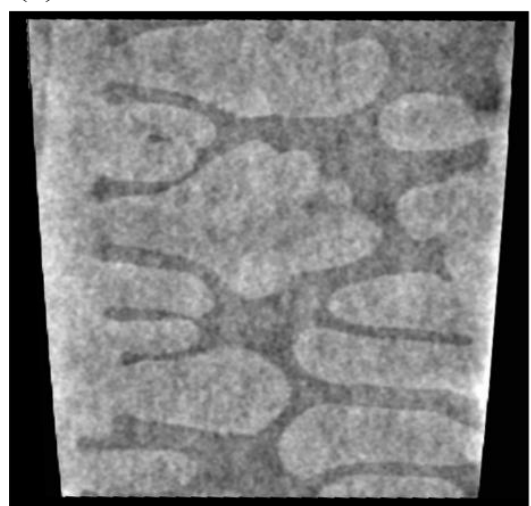

(b)

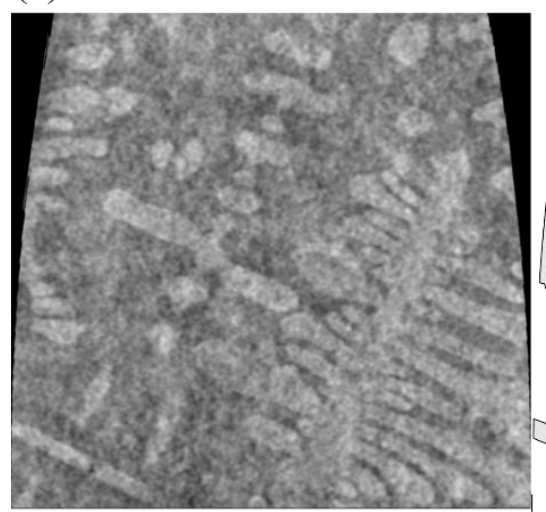

(c)

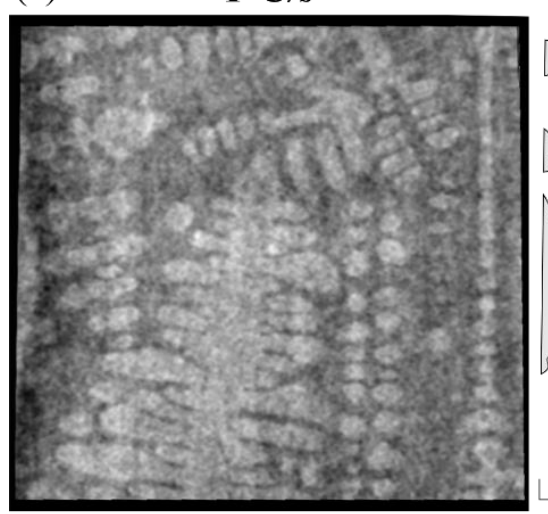

$250 \mu \mathrm{m}$
$\mathrm{T}=1340^{\circ} \mathrm{C}$

$\mathrm{f}_{\mathrm{S}} \sim 70 \%$

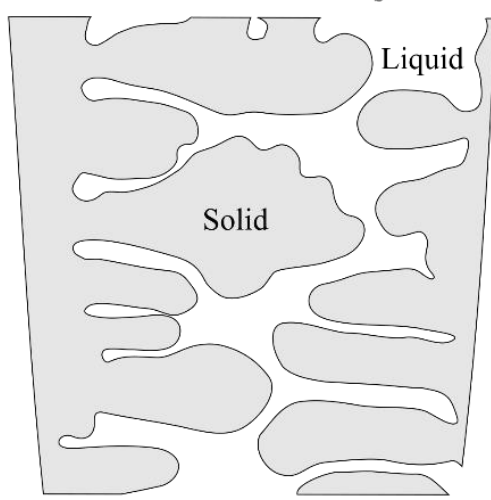

$\mathrm{f}_{\mathrm{S}} \sim 50 \%$

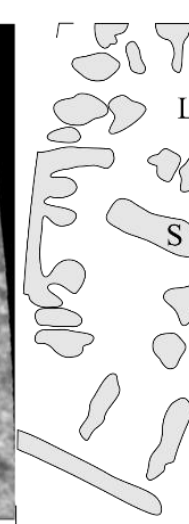

(s)

$\mathrm{L}$

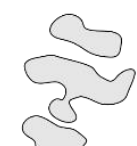

$\circ 2$

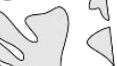

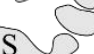

$\mathrm{L}$

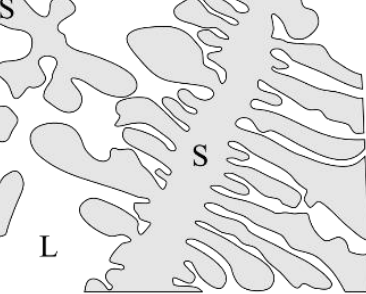

$\mathrm{f}_{\mathrm{S}} \sim 50 \%$

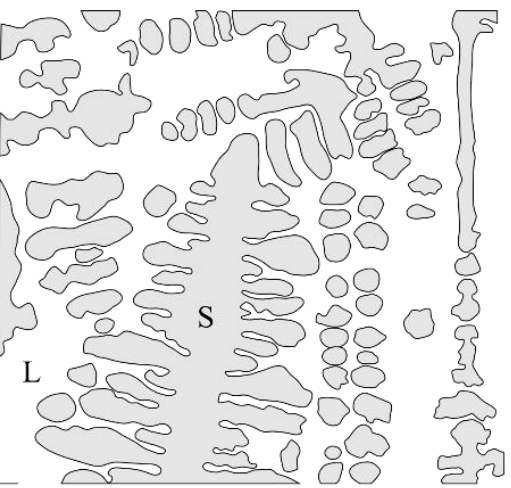

\begin{tabular}{lll} 
Liquid & L Solid & S \\
\hline
\end{tabular}

Figure 2. Dendritic solidification structures observed at $1340^{\circ} \mathrm{C}$ for three cooling rates: (a) $0.1^{\circ} \mathrm{C} / \mathrm{s}$, (b) $0.5^{\circ} \mathrm{C} / \mathrm{s}$ and (c) $1^{\circ} \mathrm{C} / \mathrm{s}$. For each sample, a slice of the reconstructed volume is shown (left). For a sake of clarity, a schematic is provided to illustrate the distribution of liquid and solid phases (right) along with a rough estimation of the average solid fraction $f_{s}$ as quantified on cross sections. Note that the solid fraction estimation given for a cooling rate of $0.1^{\circ} \mathrm{C} / \mathrm{s}$ might not be reliable as the volume of region of interest is limited.

\begin{tabular}{|c|c|c|c|}
\hline Cooling rate & $0.1 \% \mathrm{~s}$ & $0.5 \% \mathrm{~s}$ & $1 \% \mathrm{~s}$ \\
\hline$\lambda_{2}$ for $f_{s}>\sim 95 \%$ & $>110 \mu \mathrm{m}$ & $\sim 70 \mu \mathrm{m}$ & $\sim 50 \mu \mathrm{m}$ \\
\hline
\end{tabular}

Table 1. Secondary dendrite arm spacing estimated at $1290^{\circ} \mathrm{C}$, after dendritic growth and coalescence. 
The porosity observed once solidification is completed, in the samples with fine dendritic structures, i.e. cooled down at $0.5^{\circ} \mathrm{C} / \mathrm{s}$ and $1{ }^{\circ} \mathrm{C} / \mathrm{s}$, is shown in Figure 3a and Figure 3b. The pore volume fraction is estimated at $0.22 \%$ for a cooling rate of $0.5^{\circ} \mathrm{C} / \mathrm{s}$ and $0.14 \%$ for a cooling rate of $1^{\circ} \mathrm{C} / \mathrm{s}$. The pores density, however, is found higher at $1^{\circ} \mathrm{C} / \mathrm{s}\left(7800\right.$ pore $\left./ \mathrm{mm}^{3}\right)$ than at $0.5^{\circ} \mathrm{C} / \mathrm{s}\left(5500\right.$ pore $\left./ \mathrm{mm}^{3}\right)$, it means $30 \%$ more pores when the cooling rate is doubled. As illustrated in the 2D histograms shown in Figure 3c and Figure 3d, the majority of pores in both samples have an equivalent diameter below $10 \mu \mathrm{m}$ with a round shape leading to sphericity indices higher than $\sim 0.8$. Larger pores tend to be more tortuous and are associated with lower sphericity indices.

(a)

(c)
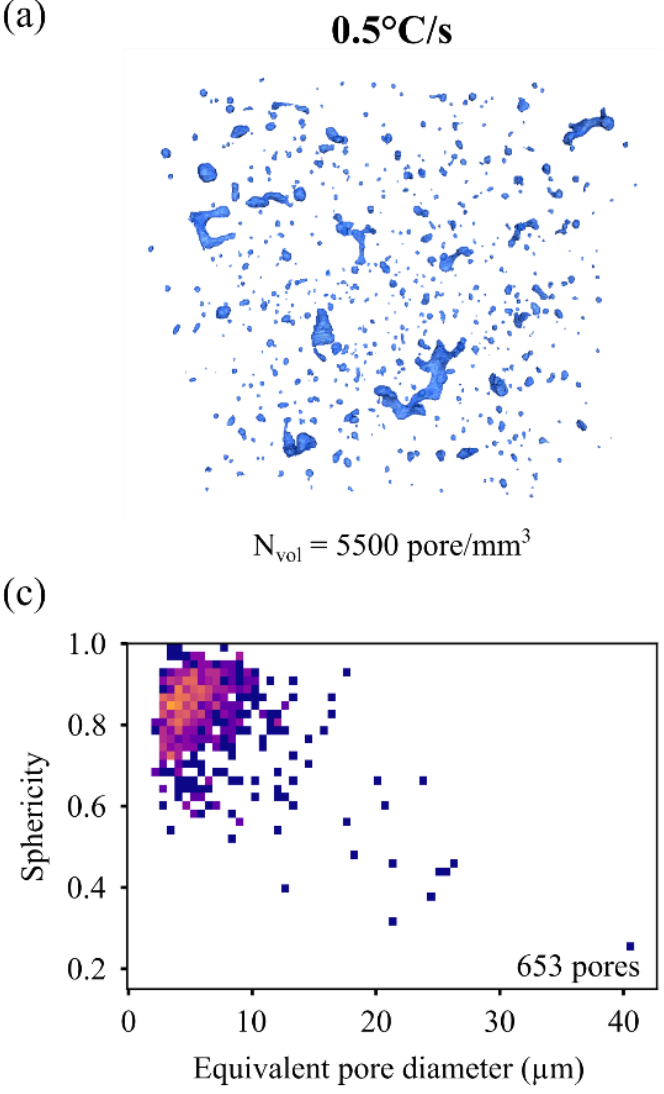

(b)

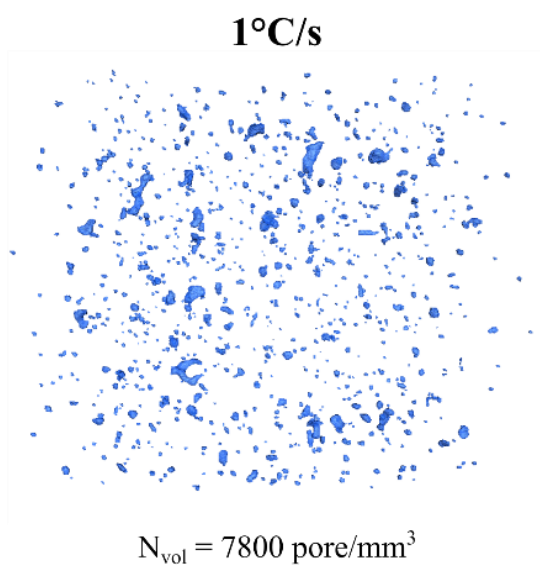

(d)

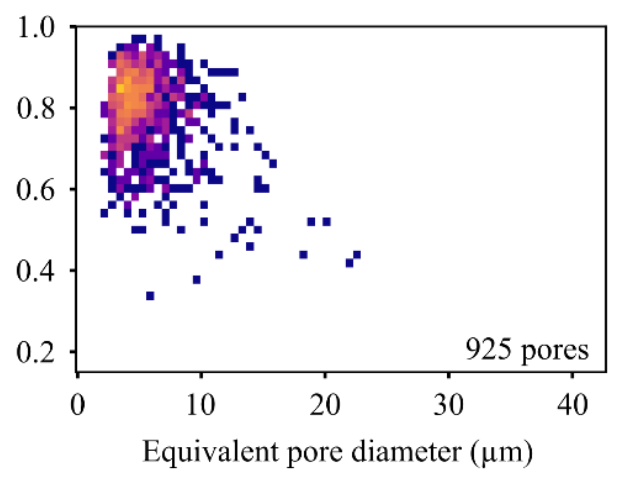

Counts

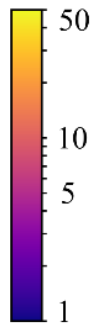

Figure 3. 3D view of the porosity after complete solidification for two cooling rates: (a) $0.5^{\circ} \mathrm{C} / \mathrm{s}$ and (b) $1^{\circ} \mathrm{C} / \mathrm{s}$. Associated $2 \mathrm{D}$ histograms providing a characterization of the pore population in terms of size and sphericity for a cooling rate of $(c) 0.5^{\circ} \mathrm{C} / \mathrm{s}$ and $(d) 1{ }^{\circ} \mathrm{C} / \mathrm{s}$.

At higher cooling rate, the porosity features more pores of smaller size. For example, the largest pore for a cooling rate of $1{ }^{\circ} \mathrm{C} / \mathrm{s}$ has an equivalent diameter of $23 \mu \mathrm{m}$ while it is $40 \mu \mathrm{m}$ for a cooling rate of $0.5^{\circ} \mathrm{C} / \mathrm{s}$. This general observation is also in agreement with the refined dendritic structure shown in Figure 2c. 


\subsection{Partitioning the pore population}

A distinction is made in Figure 4a between two populations of pores with contrasted final characteristics: namely small pores (Figure $\mathbf{4 b}$ ) and large pores (Figure 4c) and. The distinction is made because large pores, in average more tortuous, are expected to impact the creep and fatigue behavior significantly more than smaller, rounder pores. As seen in Figure 4, pores having a sphericity below 0.5 will be defined as large pores. Such a threshold based on sphericity corresponds to a critical pore equivalent diameter of about $9 \mu \mathrm{m}$.

(a)

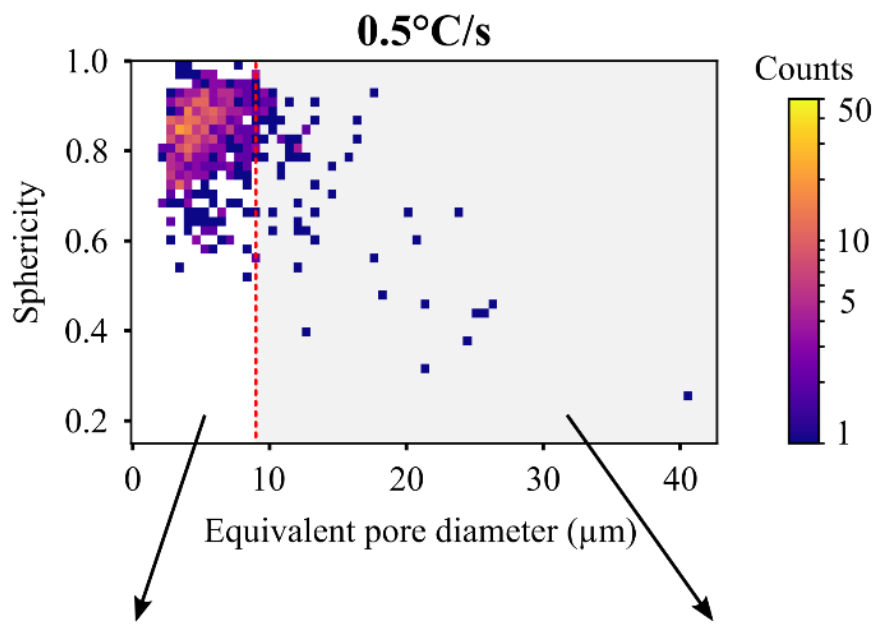

(b)

Small pores

\section{Large pores}

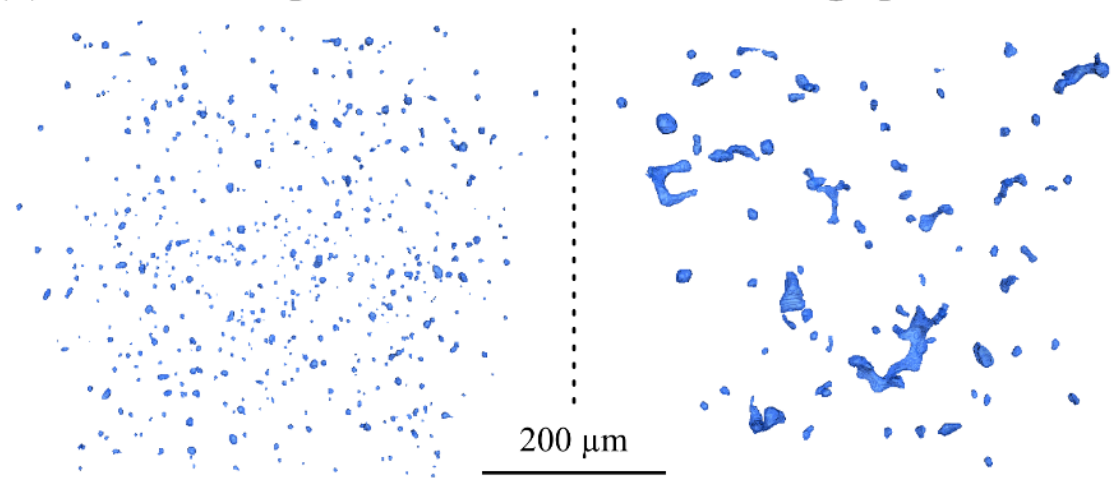

Figure 4. Partitioning the pore population into small pores and large pores illustrated sample cooled at $0.5^{\circ} \mathrm{C} / \mathrm{s}$. (a) Position of the threshold and (b) $3 \mathrm{D}$ renderings of the two subpopulations.

As shown in Figure 5, for a cooling rate of $0.5^{\circ} \mathrm{C} / \mathrm{s}$, large pores are generated between $1250^{\circ} \mathrm{C}$ and $1200^{\circ} \mathrm{C}$ while small pores are created from $1325^{\circ} \mathrm{C}$ to $1175^{\circ} \mathrm{C}$. This difference suggests that different mechanisms of pore formation and growth are activated during cooling. The two mechanisms identified in our experiment are discussed in the following section. 


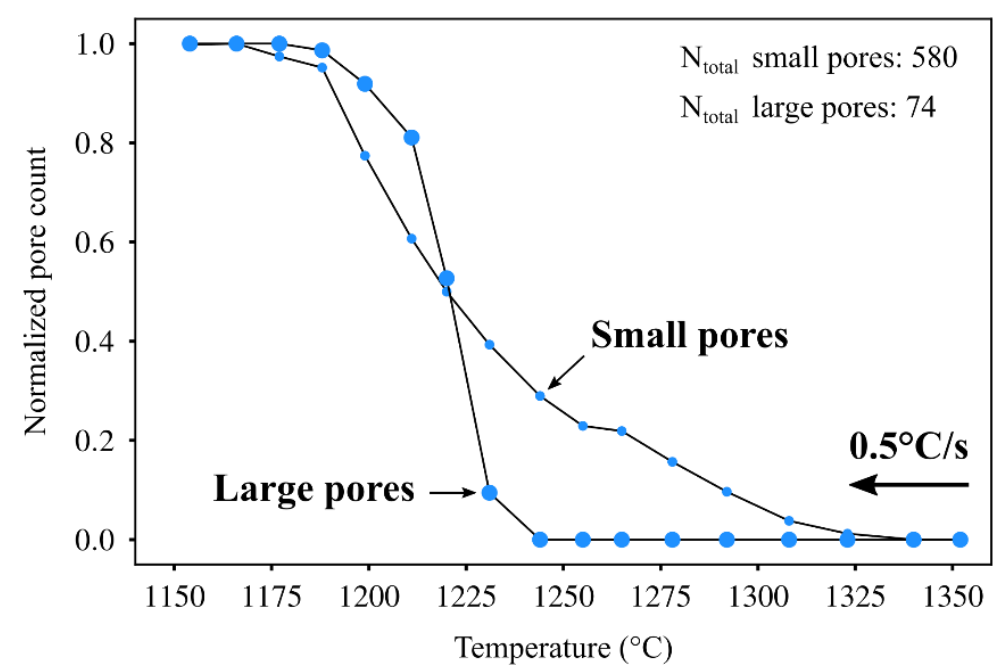

Figure 5. Normalized count of small pores and large pores during solidification at a cooling rate of $0.5^{\circ} \mathrm{C} / \mathrm{s}$. All curves are normalized by the total number of pores $\left(N_{\text {total }}\right)$ observed after complete solidification $\left(T \approx 1150^{\circ} \mathrm{C}\right)$.

\subsection{Mechanisms of pore formation}

\subsubsection{Mechanism A: porosity between secondary dendrite arms}

The first mechanism (mechanism A) is illustrated in Figure 6. 2D cross sections shown in Figure 6a and selected in the growth plane of a single dendrite, reveal how small pores are being formed in between secondary dendrite arms due to insufficient liquid flow perpendicularly to the primary dendrite trunks. This insufficient liquid feeding in between dendrite secondary arms is caused by secondary arms coalescence. At $1340^{\circ} \mathrm{C}$, a typical dendritic morphology is observed, featuring a trunk and secondary arms extending from both sides. At $1320^{\circ} \mathrm{C}$, secondary arms appear significantly larger and in smaller number, a result of growth and coalescence of the dendrite arms. At $1290^{\circ} \mathrm{C}$, residual liquid films are the last traces of the tree-shape morphology in the almost fully solidified dendrite. As pointed out by the arrows, small pores appear near the trunk of the dendrite, at positions matching liquid films observed at higher temperature between secondary arms. In the orthogonal view taken slightly away from the trunk (Figure 6b), it can be seen that pores are created with a round shape and are always located in the middle of the secondary arm alignment.

Mechanism A can be described by considering the decrease of liquid flow between secondary dendrite arms due to the coalescence of secondary dendrite arms at high temperature. As described by Mortensen [30] and later observed in situ in other alloy systems [19], the coalescence of two dendrite arms can lead to a pocket of residual 
liquid close to the trunk. This pocket is almost isolated from the liquid remaining in the interdendritic space and may evolve into a shrinkage-like pore. Because the characteristic size of the pocket is close to the thickness of the liquid film before coalescence, only small pores can be created through mechanism A. Pockets of liquid tend to adopt a rather round morphology, in relation with the progressive nature of the growth, so that pores created tend to have a high sphericity. Additionally, an average rough estimate of the local solid fraction at $1340^{\circ} \mathrm{C}$, performed on various $2 \mathrm{D}$ slices extracted from the reconstructed volume, lead to a value of 0.6 which seems a reasonable fraction according to Mortensen [30] to observe the first secondary dendrite arm coalescence events.

(a) $-1340{ }^{\circ} \mathrm{C}$
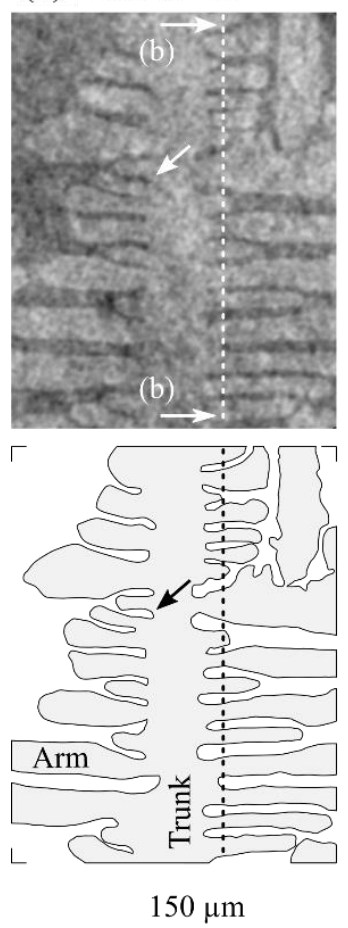

$1320{ }^{\circ} \mathrm{C}$
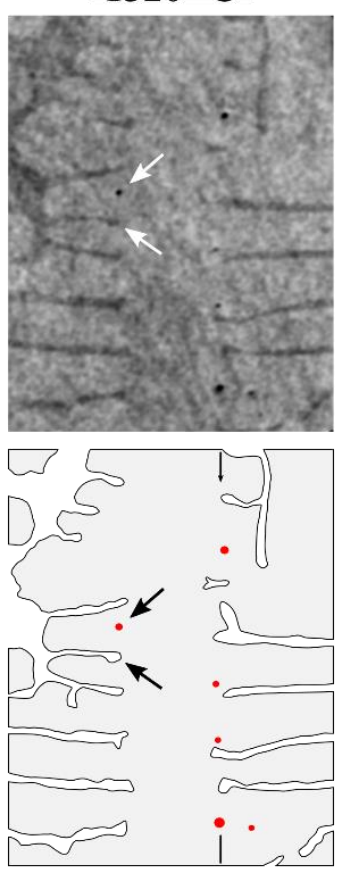

Liquid

Solid
$1290{ }^{\circ} \mathrm{C} \longrightarrow$
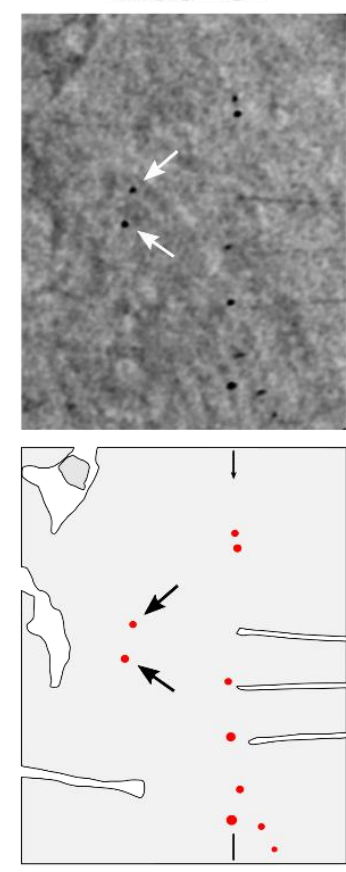

Pores -

(b)
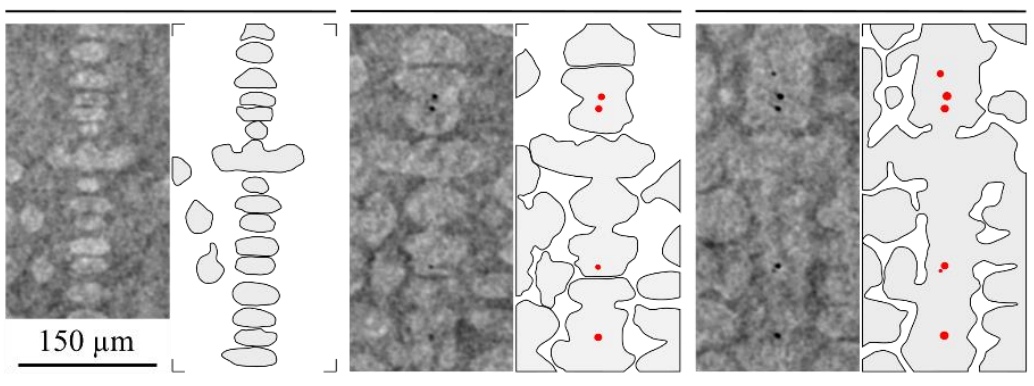

Figure 6. Mechanism A - Formation of small pores at high temperature induced by growth and coalescence of secondary dendrite arms (here for a cooling rate of $0.5^{\circ} \mathrm{C} / \mathrm{s}$ ). (a) $2 \mathrm{D}$ cross sections extracted at different temperatures showing the creation of pores within the regions containing residual liquid films, between two secondary arms before coalescence (arrows). (b) Orthogonal view of the dendrite arms, taken along the dotted line indicated in (a), suggesting that residual pockets 


\subsubsection{Mechanism B: porosity in the interdendritic space}

The characteristics of the second mechanism (mechanism B) are illustrated in Figure 7. 2D cross sections extracted from X-ray tomography 3D reconstructed volume show the evolution of interdendritic regions during the last stages of solidification. At $1290^{\circ} \mathrm{C}$, the large solid areas are associated with dendritic structures after substantial growth and coalescence (see Figure 6). The residual liquid indicates interdendritic regions where solidification happens last. At $1230^{\circ} \mathrm{C}$, a uniform contrast is observed indicating nearcomplete solidification. At $1220^{\circ} \mathrm{C}$, a large pore is formed at a position previously occupied by interdendritic liquid. As seen on the 3D rendering in Figure $\mathbf{7 b}$, the pore initially round grows significantly in size and adopt a more tortuous shape.

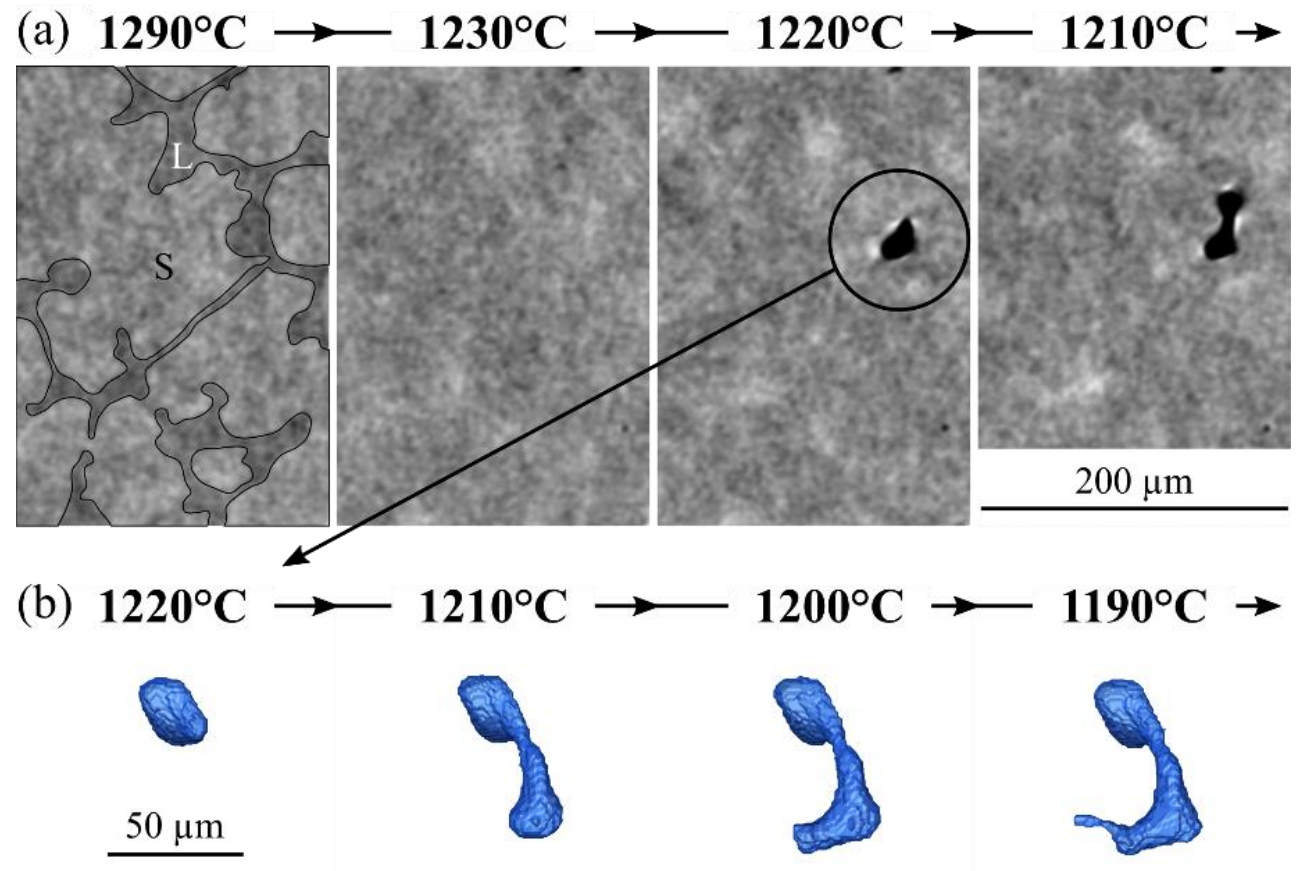

Figure 7. Mechanism B - Formation of pores at intermediate and low temperature in the interdendritic space (here for a cooling rate of $0.5^{\circ} \mathrm{C} / \mathrm{s}$ ). (a) Evolution of a single cross section showing the apparition of a pore after apparent complete solidification. (b) $3 D$ rendering of the pore showing the growth mechanism during the last stages of the solidification process.

Mechanism B is typical of shrinkage porosity generated by insufficient liquid feeding in the interdendritic space during the last stages of solidification and promoted by thermal contraction [31]. As expected, this mechanism is activated mostly at low temperature $\left(1220^{\circ} \mathrm{C}\right.$ in the example shown in Figure 7$)$, in the last stages of solidification. In Figure 7a, thin films of residual liquid are likely 
stables down to $1190^{\circ} \mathrm{C}$, although the spatial resolution and sensitivity of our analysis is insufficient to detect them. The presence of residual liquid is required to support the growth mechanism taking place in-between dendrites. We observed that Mechanism B can lead to large pores with tortuous shapes, as shown in Figure $\mathbf{7 b}$, as well as small pores with a spherical-like shape. The size and shape of the pore depend mostly on the local geometrical and topological configuration of the interdendritic volume and on the surrounding liquid feeding conditions.

\subsection{Effect of cooling rate on pore nucleation}

The evolution of the normalized number of small pores and large pores is reported in Figure 8a and Figure 8b respectively for two cooling rates: $0.5^{\circ} \mathrm{C} / \mathrm{s}$ and $1{ }^{\circ} \mathrm{C} / \mathrm{s}$. Large pores are formed in a relatively narrow temperature range, roughly between $1230^{\circ} \mathrm{C}$ and $1200^{\circ} \mathrm{C}$, and the nucleation rate appears similar for both cooling rates (see Figure 8b). In contrast, small pores are generated in a wide range of temperature, between $1320^{\circ} \mathrm{C}$ and $1180^{\circ} \mathrm{C}$, and the kinetics of nucleation seems to be sensitive depend significantly on the cooling rate (see Figure 8a). At slower cooling rates, a higher number of small pores are generated at higher temperature: for example, $20 \%$ of the final pore count is reached at $1270^{\circ} \mathrm{C}$ for a cooling rate of $0.5^{\circ} \mathrm{C} / \mathrm{s}$ while this value is reached at $1230^{\circ} \mathrm{C}$ for a cooling rate of $1{ }^{\circ} \mathrm{C} / \mathrm{s}$.

(a)

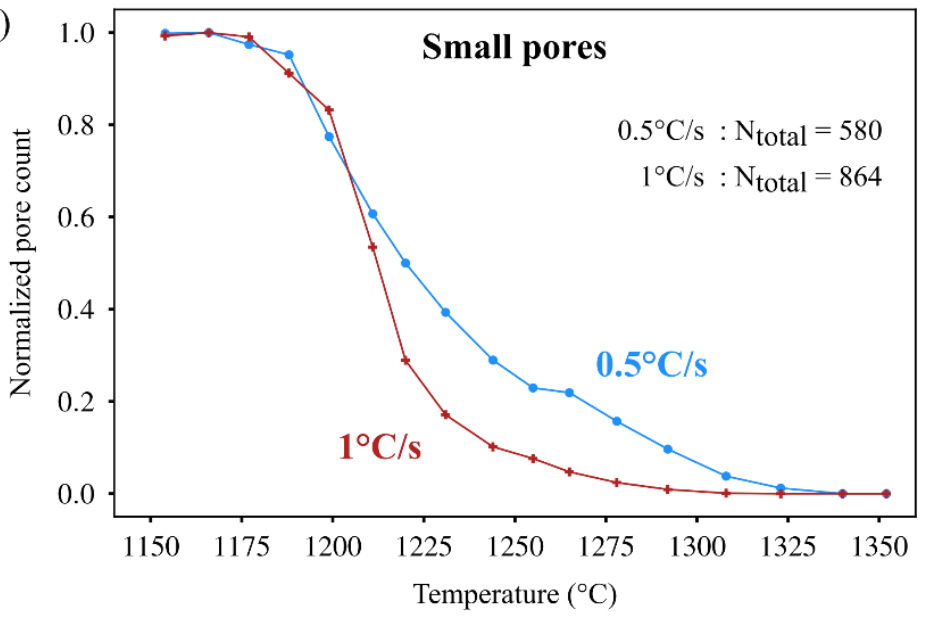

(b)

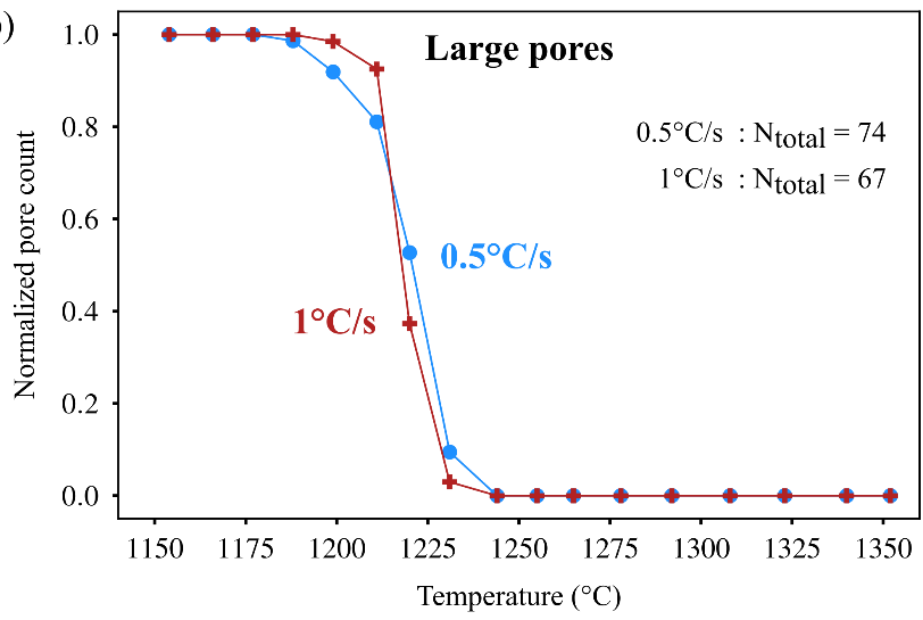

Figure 8. Evolution of the normalized number of (a) small pores and (b) large pores during solidification at a cooling rate of $0.5^{\circ} \mathrm{C} / \mathrm{s}$ and $1{ }^{\circ} \mathrm{C} / \mathrm{s}$. All curves are normalized by the total number of pores $\left(N_{\text {total }}\right)$ observed after complete solidification $\left(T \approx 1150^{\circ} \mathrm{C}\right)$.

The kinetics of nucleation is consistent with the two mechanisms identified. Large pores are obtained through mechanism B at the end of solidification only. On the contrary, small pores are created by 
both mechanisms, i.e. at high temperature through mechanism A and at lower temperature through mechanism B.

Our purpose is now to make a deconvolution between the two mechanisms for the generation of small pores because both mechanisms A and B contribute to the formation of small pores. This should help to determine characteristic temperatures for the nucleation of small pores through each individual mechanism. To do so, a simple model is introduced below to further comment on the effect of the cooling rate on the nucleation of small pores. Both mechanism A and mechanism B are assumed to follow a Gaussian nucleation rate as suggested by equation (1).

$$
\dot{N} \propto \frac{1}{\sigma \sqrt{2 \pi}} e^{-\frac{(T-\mu)^{2}}{2 \sigma^{2}}}
$$

In equation (1), $\mu$ is the mean and $\sigma$ is the standard deviation of the Gaussian distribution. The total number of pores created is the sum of both mechanisms. Relying on previous hypotheses, a least-square fit was performed for the two cooling rates investigated $(0.5$ and $1{ }^{\circ} \mathrm{C} / \mathrm{s}$ ) and the parameters for the nucleation rates identified. The result are presented in Figure 9a-b while the mean value $\mu$ and the standard deviation $\sigma$ for each mechanisms are reported in Table 2. 
(a)

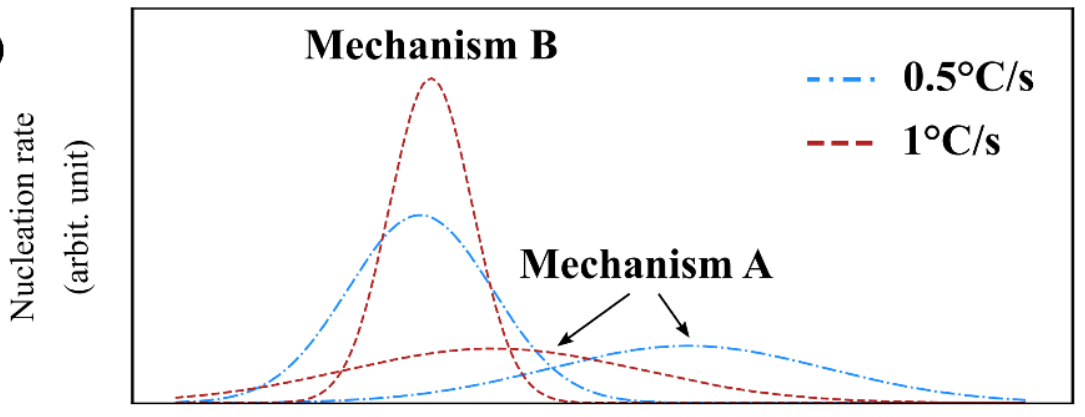

(b)

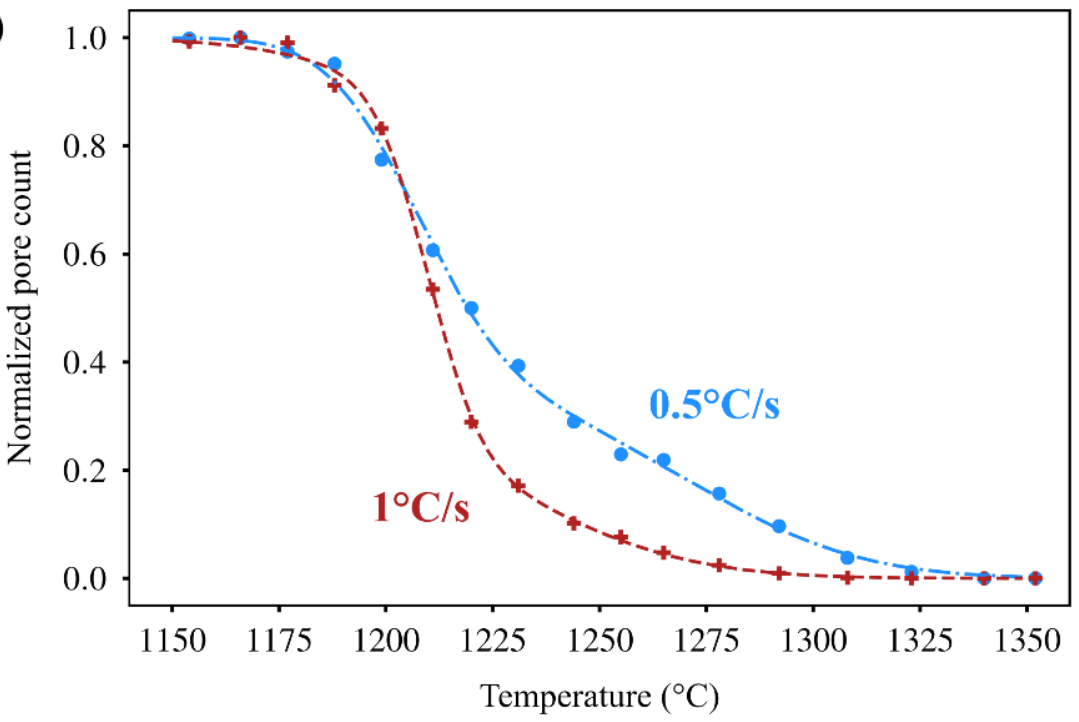

Figure 9. The evolution of the number of small pores is separated into contributions from mechanism A and mechanism B. A gaussian nucleation rate was assumed for both mechanisms and the resulting least-square fit performed with the experimental pore counts is shown.

\begin{tabular}{|c|c|c|c|c|}
\hline \multirow{2}{*}{} & \multicolumn{2}{|c|}{ Mechanism A } & \multicolumn{2}{c|}{ Mechanism B } \\
\cline { 2 - 5 } & $\mu_{A}$ & $\sigma_{A}$ & $\mu_{B}$ & $\sigma_{B}$ \\
\hline $0.5^{\circ} \mathrm{C} / \mathrm{s}$ & $1270^{\circ} \mathrm{C}$ & $32^{\circ} \mathrm{C}$ & $1207^{\circ} \mathrm{C}$ & $17^{\circ} \mathrm{C}$ \\
\hline $1{ }^{\circ} \mathrm{C} / \mathrm{s}$ & $1225^{\circ} \mathrm{C}$ & $34^{\circ} \mathrm{C}$ & $1210^{\circ} \mathrm{C}$ & $10^{\circ} \mathrm{C}$ \\
\hline
\end{tabular}

Table 2. Mean values $\mu$ and standard deviations $\sigma$ of the Gaussian nucleation rates identified during the deconvolution process of small pores shown in Figure 9.

On the one hand, mechanism B does not seem sensitive to the cooling rate as shown by relatively similar mean values and standard deviations. This is in agreement with the observation made on the large pore population (created only through mechanism B) with a mean value found to be about $1220^{\circ} \mathrm{C}$. On the other hand, our analysis suggests that mechanism A depends on the cooling rate though the cooling rate was just doubled. The mean 
value for the deconvolution is found to be $1270^{\circ} \mathrm{C}$ for a cooling rate of $0.5^{\circ} \mathrm{C} / \mathrm{s}$ whereas it is only $1225^{\circ} \mathrm{C}$ for a cooling rate of $1^{\circ} \mathrm{C} / \mathrm{s}$.

To summarize, we believe that both mechanism A and mechanism B are shrinkage-type of porosity triggered by similar fundamental causes, such as insufficient liquid feeding in confined areas, although the local conditions suitable for a pore nucleation differs between the two mechanisms. The development of favorable local conditions, i.e. limited liquid feeding, explains the contrasted sensitivity of mechanism A and mechanism B to the cooling rate. First, note that the nucleation of gas pores is unlikely to happen here as the difference of hydrogen solubility between the liquid and the solid phase is relatively limited in Ni-based alloys [32] contrary to what is reported for Al-alloys where gas pores have often been reported, see e.g. $[15,30]$. Second, we did not observe spherical pores in the liquid at high temperature during the early stages of solidification.

As stated before, mechanism A is strongly linked with the coalescence of secondary dendrite arms since it reduces liquid flow normal to the primary dendrite trunks. Close to the dendrite trunk, around residual pockets of liquid, conditions to ensure a proper liquid feeding in-betweeen dendrite secondary arms are not fulfilled anymore (strong decrease of the permeability for flow perpendicularly to the primary trunks due to secondary arms coalesecence), even if the overall solid fraction is still relatively low ( 60\%). Thus mechanism A depends on secondary arm coarsening, a phenomenon which occurs during the early stages of solidification and which starts earlier, i.e. at higher temperature when the cooling rate is divided by a factor 2 , see [33].

Mechanism B is governed by the permeability of the dendritic structures for flow parallel to primary trunks during the last stages of solidification, at large overall solid fractions, typically when $f_{s}>90 \%$. Ganesan et al. [34] have studied the permeability (denoted $K$ ) for flow parallel to primary dendrites arms and they derived an analytical equation linking the permeability to the primary dendrite arm spacing (denoted $\lambda_{I}$ ), the fraction of liquid (denoted $f_{L}$, hence solid $f_{S}$ ) and other geometrical parameters. This equation shows that the permeability $K$ for flow parallel to primary dendrite arms, which is thought to be the root cause of pores forming through mechanism B, is proportional to $\lambda_{1}{ }^{2}$. The fact that mechanism $\mathrm{B}$ is not significantly sensitive when the cooling rate changes from $0.5^{\circ} \mathrm{C} / \mathrm{s}$ to $1{ }^{\circ} \mathrm{C} / \mathrm{s}$, contrary to mechanism A, can be rationalized. Indeed, we first estimated the primary dendrite arm spacing $\lambda_{1}$ on $2 \mathrm{D}$ cross sections, see typically Figure 2, for samples cooled at $0.5^{\circ} \mathrm{C} / \mathrm{s}$ to $1^{\circ} \mathrm{C} / \mathrm{s}$. Our rough estimation of $\lambda_{I}$ gives: $\lambda_{I}\left(0.5^{\circ} \mathrm{C} / \mathrm{s}\right) \approx 200-300 \mu \mathrm{m}$ and $\lambda_{I}\left(1^{\circ} \mathrm{C} / \mathrm{s}\right)$ $\approx 150-200 \mu \mathrm{m}$ are consistent with the ones reported in reference [28] which has reviewed the results obtained in many different studies. Thus doubling the cooling rate does not lead to a drastic change of 
the primary dendrite arm spacing, therefore such a variation does not sufficiently change the permeability values to alter the sensitivity of mechanism B to cooling rate change, at least in the range explored in the present work. Mechanism B is thus less sensitive to limited variations of cooling rate than mechanism $\mathrm{A}$.

\subsection{Effect of cooling rate on pore growth}

The kinetics of growth was evaluated with the tracking method described in section 2.3 for each pore with a final equivalent diameter larger than $6 \mu \mathrm{m}$. For pores with a smaller final diameter, the spatial resolution of our analysis was considered insufficient to monitor the process. As illustrated in Figure 10, the kinetics of growth can vary significantly from pore to pore. We found that equation (2) could be used to fit efficiently the majority of the experimental data.

$$
D_{e q}^{n}=1-e^{\alpha\left(T-T_{0}\right)}
$$

where $D_{e q}^{n}$ is the normalized equivalent diameter, $T_{0}$ is the nucleation temperature and $\alpha$ is a parameter governing the kinetics of pore growth. $40 \%$ of the pores are detected directly with their final size or, alternatively, only a single point is available to fit their size evolution (see typically cases where $\alpha=0.3$ in Figure 10). In such cases, the temporal resolution of our analysis was deemed insufficient to robustly describe the kinetics of pore growth and the associated pores were not considered further in the analysis.
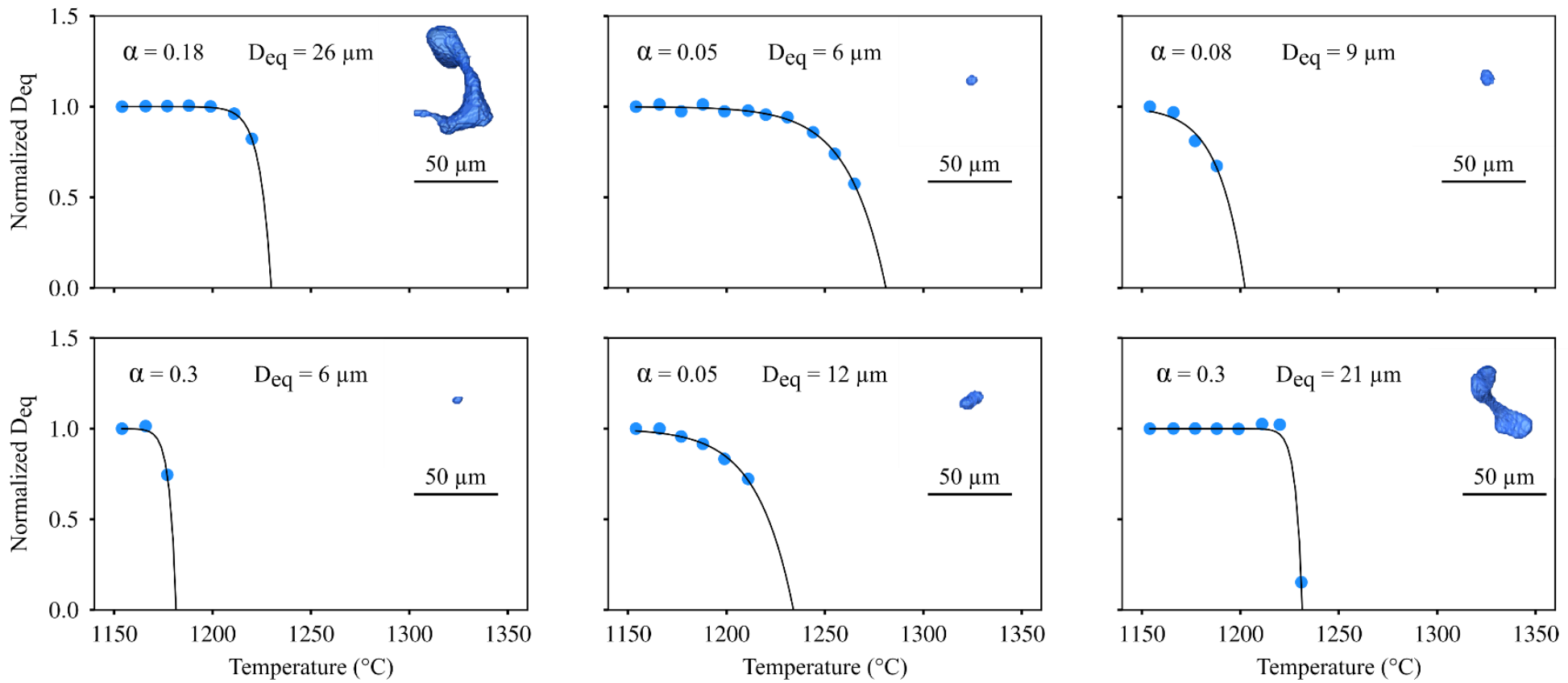

Figure 10. Illustration of the tracking method used to monitor the growth of individual pores. An exponential-like function with two parameters was fitted to the 
A plot of the coefficients fitted for 256 pores $(60 \%$ of the total population) is provided in Figure $\mathbf{1 1}$ for two cooling rates. Each dot in Figure $\mathbf{1 1}$ has a size proportional to the final equivalent diameter of the pore. As discussed above, large pores nucleate in a narrow band of temperature compared to small pores. No apparent correlation is detected between the final size of the pore and the $\alpha$ coefficient. For both cooling rates, we see that small pores nucleating at high temperature (roughly $>1250^{\circ} \mathrm{C}$ ) have low $\alpha$ coefficient, typically below 0.1 . At lower temperatures, a large dispersion in the values of $\alpha$ is observed in a range between 0.05 and 0.3 . As the temperature decreases, we see a tendency to observe higher coefficients. This suggests that pore growth is faster, in average, for mechanism B than mechanism A.

(a)

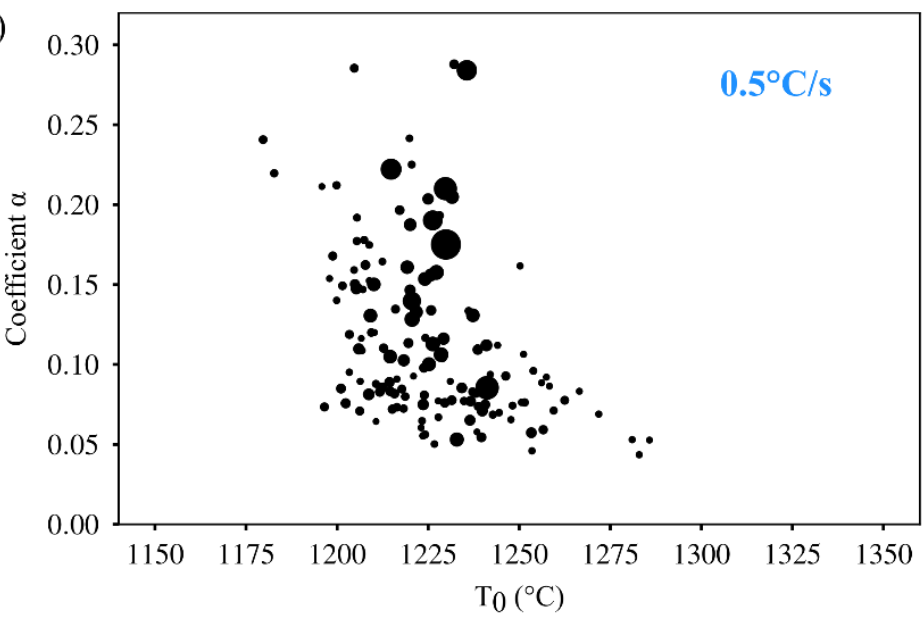

(b)

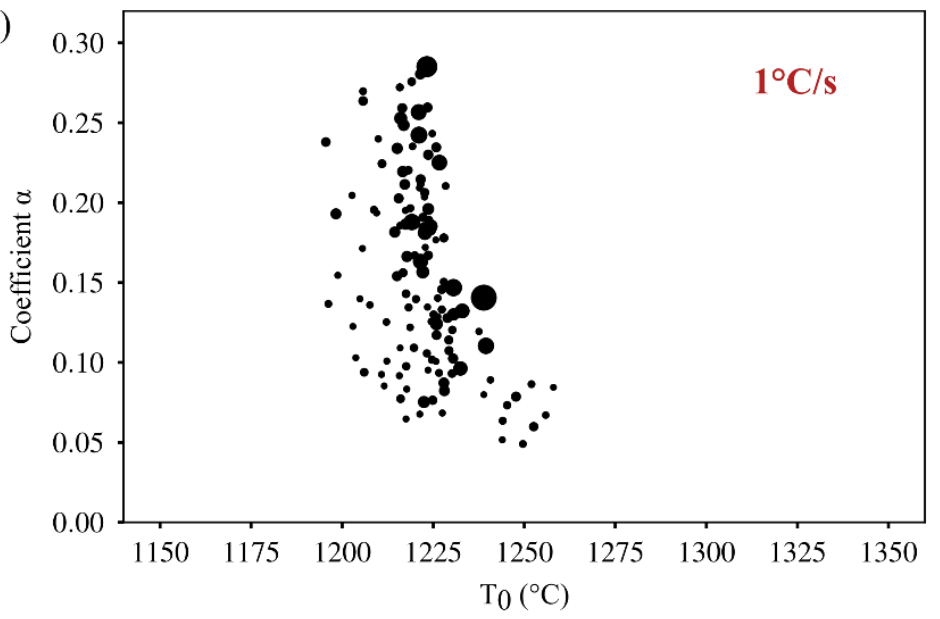

Figure 11. Distribution of parameters $\alpha$ and $T_{0}$ from equation (1), fitted on individual pores using the tracking method, for two cooling rate: (a) $0.5^{\circ} \mathrm{C} / \mathrm{s}$ and (b) $1^{\circ} \mathrm{C} / \mathrm{s}$. The size of each dot is proportional to the final equivalent diameter of the pore.

Among the population of pores considered in our growth analysis, at higher cooling rate, the growth seems faster on average: the mean value of $\alpha$ is 0.18 for a cooling rate of $1^{\circ} \mathrm{C} / \mathrm{s}$ but it is only 0.13 for a cooling rate of $0.5^{\circ} \mathrm{C} / \mathrm{s}$. Overall, it appears that the distribution of parameters describing pore growth is significantly affected by the cooling rate considered., even within the restricted range of cooling rate considered in the present work. 


\title{
4. Conclusions
}

Based on the work reported above, the following conclusions can be drawn:

- Time-resolved in situ microtomography can be used to track the nucleation and growth of individual pores during solidification of industrial-grade Ni-based superalloys at representative cooling rates $\left(1^{\circ} \mathrm{C} / \mathrm{s}\right)$.

- Phase contrast imaging, in the absence of X-ray absorption contrast, provides valuable data on the evolution of dendritic structures during solidification.

- Two mechanisms of pore formation have been identified. Both mechanisms lead to shrinkage pores in confined regions with a high local solid fraction. Mechanism A is associated with the insufficient liquid flow normal to the primary dendrite trunks caused by the coalescence of secondary dendrite arms at temperature above approximately $1220^{\circ} \mathrm{C}$. Mechanism B is related to insufficient feeding of the interdendritic space during the last stages of solidification, at lower temperatures.

- Small pores usually exhibit a high sphericity and are generated through both mechanism A and mechanism B in a large range of temperature. Large pores often have a tortuous shape and are formed through mechanism B only, in a narrow range of temperature around $1220^{\circ} \mathrm{C}$.

- A variation of the cooling rate by a factor 2 does not affect the nucleation rate of large pores and small pores obtained through mechanism $B$ although it has a significant impact on the nucleation rate of small pores obtained through mechanism A. As the cooling rate decreases, small pores are nucleated at higher temperature.

- The kinetics of individual pore growth has been characterized. This kinetics is faster for mechanism B compared to mechanism A.

\begin{abstract}
Aknowledgements
This work was performed within the framework of the Center of Excellence of Multifunctional Architectured Materials "CEMAM" $\mathrm{n}^{\circ} \mathrm{AN}-10-\mathrm{LABX}-44-01$ funded by the "Investments for the Future Program', The European Synchrotron Radiation Facility (ESRF) is gratefully acknowledged for offering beam-time associated to the MA3483 proposal.
\end{abstract}




\section{References}

[1] M.R. Orlov, Pore Formation in Single-Crystal Turbine Rotor Blades during Directional Solidification, 2008 (2008) 56-60. doi:10.1134/S0036029508010114.

[2] K. Prasad, R. Sarkar, K. Gopinath, Role of shrinkage pores , carbides on cyclic deformation behaviour of conventionally cast nickel base superalloy CM247LC s at $870{ }^{\circ} \mathrm{C}, 654$ (2016) 381-389. doi:10.1016/j.msea.2015.12.054.

[3] L. Kunz, P. Lukáš, R. Konečná, High-cycle fatigue of Ni-base superalloy Inconel 713LC, Int. J. Fatigue. 32 (2010) 908-913. doi:10.1016/j.ijfatigue.2009.02.042.

[4] A. Epishin, T. Link, Mechanisms of high-temperature creep of nickel-based superalloys under low applied stresses, Philos. Mag. $84 \quad$ (2004) 1979-2000. doi:10.1080/14786430410001663240.

[5] R.C. Reed, Single-crystal superalloys for blade applications, in: The Superalloys, 2009: pp. 121-216. doi:10.1017/cbo9780511541285.005.

[6] H. Buck, P. Wollgramm, A.B. Parsa, G. Eggeler, A quantitative metallographic assessment of the evolution of porosity during processing and creep in single crystal Ni-base super alloys, Materwiss. Werksttech. 46 (2015) 577-590. doi:10.1002/mawe.201500379.

[7] J.B. le Graverend, J. Adrien, J. Cormier, Ex-situ X-ray tomography characterization of porosity during hightemperature creep in a Ni-based single-crystal superalloy: Toward understanding what is damage, Mater. Sci. Eng. A. 695 (2017) 367-378. doi:10.1016/j.msea.2017.03.083.

[8] L. Mujica Roncery, I. Lopez-Galilea, B. Ruttert, D. Bürger, P. Wollgramm, G. Eggeler, W. Theisen, On the Effect of Hot Isostatic Pressing on the Creep Life of a Single Crystal Superalloys, Adv. Eng. Mater. 18 (2016) 1381-1387. doi:10.1002/adem.201600071.

[9] S. Steuer, P. Villechaise, T.M. Pollock, J. Cormier, Benefits of high gradient solidification for creep and low cycle fatigue of AM1 single crystal superalloy, Mater. Sci. Eng. A. 645 (2015) 109-115. doi:10.1016/j.msea.2015.07.045.

[10] L. Salvo, P. Cloetens, E. Maire, S. Zabler, J.J. Blandin, J.Y. Buffière, W. Ludwig, E. Boller, D. Bellet, C. Josserond, Xray micro-tomography an attractive characterisation technique in materials science, Nucl. Instruments Methods Phys. Res. Sect. B Beam Interact. with Mater. Atoms. 200 (2003) 273-286. doi:10.1016/S0168-583X(02)01689-0.

[11] T. Link, S. Zabler, A. Epishin, A. Haibel, M. Bansal, X. Thibault, Synchrotron tomography of porosity in singlecrystal nickel-base superalloys, Mater. Sci. Eng. A. 425 (2006) 47-54. doi:10.1016/j.msea.2006.03.005.

[12] J.L. Liu, J. Meng, J.J. Yu, Y.Z. Zhou, X.F. Sun, Influence of solidification conditions and alloying elements Re and $\mathrm{Ti}$ on 
micropores formed during homogenization of Ni base single crystal superalloy, J. Alloys Compd. 746 (2018) 428-434. doi:10.1016/j.jallcom.2018.02.221.

[13] K. Matuszewski, H. Matysiak, J. Jaroszewicz, W. De Nolf, K. Kubiak, K.J. Kurzydłowski, Influence of Bridgman process conditions on microstructure and porosity of single crystal Ni-base superalloy CMSX-4, Int. J. Cast Met. Res. 27 (2014) 329-335. doi:10.1179/1743133614y.0000000112.

[14] E.W.J. Miller, J. Beech, In-situ radiographic observations of alloy solidification, Metallography. 5 (1972) 298-300. doi:10.1016/0026-0800(72)90009-2.

[15] P.D. Lee, J.D. Hunt, Hydrogen porosity in directional solidified aluminium-copper alloys: In situ observation, Acta Mater. 45 (1997) 4155-4169. doi:10.1016/S13596454(97)00081-5.

[16] L. Salvo, M. Di Michiel, M. Scheel, P. Lhuissier, B. Mireux, M. Suéry, Ultra Fast In Situ X-Ray Micro-Tomography: Application to Solidification of Aluminium Alloys, Mater. Sci. Forum. 706-709 (2012) 1713-1718. doi:10.4028/www.scientific.net/msf.706-709.1713.

[17] B. Cai, J. Wang, A. Kao, K. Pericleous, A.B. Phillion, R.C. Atwood, P.D. Lee, 4D synchrotron X-ray tomographic quantification of the transition from cellular to dendrite growth during directional solidification, Acta Mater. 117 (2016) 160-169. doi:10.1016/j.actamat.2016.07.002.

[18] R. Daudin, S. Terzi, P. Lhuissier, J. Tamayo, M. Scheel, N.H. Babu, D.G. Eskin, L. Salvo, Particle-induced morphological modification of $\mathrm{Al}$ alloy equiaxed dendrites revealed by subsecond in situ microtomography, Acta Mater. 125 (2017) 303-310. doi:10.1016/j.actamat.2016.12.005.

[19] N. Limodin, L. Salvo, E. Boller, M. Suéry, M. Felberbaum, S. Gailliègue, K. Madi, In situ and real-time 3-D microtomography investigation of dendritic solidification in an Al-10 wt.\% Cu alloy, Acta Mater. 57 (2009) 2300-2310. doi:10.1016/j.actamat.2009.01.035.

[20] N. Limodin, L. Salvo, M. Suéry, M. DiMichiel, In situ investigation by X-ray tomography of the overall and local microstructural changes occurring during partial remelting of an Al-15.8 wt.\% Cu alloy, Acta Mater. 55 (2007) 3177-3191. doi:10.1016/j.actamat.2007.01.027.

[21] A.G. Murphy, W.U. Mirihanage, D.J. Browne, R.H. Mathiesen, Equiaxed dendritic solidification and grain refiner potency characterised through in situ X-radiography, Acta Mater. 95 (2015) 83-89. doi:10.1016/j.actamat.2015.04.060.

[22] M.A. Azeem, P.D. Lee, A.B. Phillion, S. Karagadde, P. Rockett, R.C. Atwood, L. Courtois, K.M. Rahman, D. Dye, Revealing dendritic pattern formation in $\mathrm{Ni}, \mathrm{Fe}$ and Co alloys using synchrotron tomography, Acta Mater. 128 (2017) 241248. doi:10.1016/j.actamat.2017.02.022.

[23] E. Chauvet, C. Tassin, J.J. Blandin, R. Dendievel, G. Martin, 
Producing Ni-base superalloys single crystal by selective electron beam melting, Scr. Mater. 152 (2018) 15-19. doi:10.1016/j.scriptamat.2018.03.041.

[24] E. Chauvet, P. Kontis, E.A. Jägle, B. Gault, D. Raabe, C. Tassin, J.J. Blandin, R. Dendievel, B. Vayre, S. Abed, G. Martin, Hot cracking mechanism affecting a non-weldable Ni-based superalloy produced by selective electron Beam Melting, Acta Mater. 142 (2018) 82-94. doi:10.1016/j.actamat.2017.09.047.

[25] P. Kontis, E. Chauvet, Z. Peng, J. He, A. Kwiatowski da Silva, Dierk Raabe, C. Tassin, J-J. Blandin, S. Abed, R. Dendievel, B. Gault, G. Martin, Atomic-scale grain boundary engineering to overcome hot cracking in additively manufactured superalloys, Acta Mater. 177 (2019) 209-221 https://doi.org/10.1016/j.actamat.2019.07.041.

[26] A. Mirone, E. Brun, E. Gouillart, P. Tafforeau, J. Kieffer, The PyHST2 hybrid distributed code for high speed tomographic reconstruction with iterative reconstruction and a priori knowledge capabilities, Nucl. Instruments Methods Phys. Res. Sect. B Beam Interact. with Mater. Atoms. 324 (2014) 41-48. doi:10.1016/j.nimb.2013.09.030.

[27] D. Paganin, S.C. Mayo, T.E. Gureyev, P.R. Miller, S.W. Wilkins, Simultaneous phase and amplitude extraction from a single defocused image of a homogeneous object, $\mathrm{J}$. Microsc. 206 (2002) 33-40. doi:10.1046/j.13652818.2002.01010.x.

[28] J. Schindelin, I. Arganda-Carreras, E. Frise, V. Kaynig, M. Longair, T. Pietzsch, S. Preibisch, C. Rueden, S. Saalfeld, B. Schmid, J.Y. Tinevez, D.J. White, V. Hartenstein, K. Eliceiri, P. Tomancak, A. Cardona, Fiji: An open-source platform for biological-image analysis, Nat. Methods. 9 (2012) 676-682. doi:10.1038/nmeth.2019.

[29] H.S. WHITESELL, L. LI, R.A. OVERFELT, Influence of Solidification Variables on the Dendrite Arm Spacings of NiBased Superalloys, Metall. Mater. Trans. B. 31B (2000) 546551. doi:10.1080/00304947109356052.

[30] A. Mortensen, On the influence of coarsening on microsegregation, Metall. Trans. A. 20 (1989) 247-253. doi:10.1007/BF02670250.

[31] J.A. Dantzig, M. Rappaz, Solidification, 2nd Editio, EPFL Press, 2016. http://www.solidification.org/.

[32] J. Campbell, Complete Casting Handbook: Metal Casting Processes, Metallurgy, Techniques and Design: Second Edition, 2015. doi:10.1016/C2014-0-01548-1.

[33] J.J. Xu, T.M. Wang, J. Zhu, H.L. Xie, T.Q. Xiao, T.J. Li, In situ study on secondary dendrite arm coarsening of $\mathrm{Sn}-\mathrm{Bi}$ alloy by synchrotron microradiography, Mater. Res. Innov. 15 (2011) 156-159. doi:10.1179/143307511x12998222919155.

[34] S. Ganesan, C.L. Chan, D.R. Poirier, Permeability for flow 
parallel to primary dendrite arms, Mater. Sci. Eng. A. 151 (1992) 97-105. doi:10.1016/0921-5093(92)90186-5. 